Brugman, M., Caron, S.L., Rademakers, J. Emerging adolescent sexuality: a comparison of Americanand 7 Dutch college women's experiences. International Journal of Sexual Health: 2010, 22(1), 32-46

\begin{tabular}{|l|l|}
\hline $\begin{array}{l}\text { Postprint } \\
\text { Version }\end{array}$ & 1.0 \\
\hline $\begin{array}{l}\text { Journal website } \\
\text { http://www.informaworld.com/smpp/content } \sim \mathrm{db}=\text { all?content=10.1080/1931761 }\end{array}$ \\
\hline Pubmed link & $\underline{\underline{903403974}}$ \\
\hline DOI & $10.1080 / 19317610903403974$ \\
\hline
\end{tabular}

This is a NIVEL certified Post Print, more info at http://www.nivel.eu

\title{
Emerging Adolescent Sexuality: A Comparison of American and Dutch College Women's Experiences
}

\author{
MARGARET BRUGMAN ${ }^{\text {A }}$; SANDRA L. CARON ${ }^{\text {A }}$;AANY RADEMAKERS ${ }^{\text {B }}$ \\ ${ }^{\text {a }}$ University of Maine, Orono, Maine, USA \\ ${ }^{\mathrm{b}}$ NIVEL, Utrecht, The Netherlands
}

\begin{abstract}
The United States has the highest rates of teen pregnancy, births, and abortions of all industrialized countries. On the contrary, The Netherlands has the lowest rates. Using qualitative and quantitative methods, this retrospective study investigated American and Dutch college women's sexual behavior, attitudes, and comfort to better understand the factors that lead to the disparity between these two countries. Survey results revealed that the American sample experienced sexual behaviors at a younger age and with more partners, whereas the Dutch sample showed a better use of contraceptives during high school, more talk with their parents, and greater sexuality education. Several distinctly different themes emerged between the U.S. and Dutch women from the in-depth interviews. Themes about U.S. girls included: driven by hormones and peers; unprepared; satisfying him; and uncomfortable and silent parents. Some themes about Dutch girls were: motivated by love; control of my own body; parents as supporters and educators; and books at young ages. Implications for what the United States could be doing to promote sexual health are discussed.
\end{abstract}

Of all Western countries, the United States has the highest rates of teenage pregnancy, births, and abortions. Although significant decreases have occurred in the past decade, the United States still has the highest rates among industrialized countries. On the contrary, The Netherlands has the lowest rates of teen pregnancy, births, abortions, and sexually transmitted infections (STIs) of all industrialized countries (Feijoor, Alford, \& Hauser, 2009). In 2005, the U.S. teen pregnancy rate was six times higher and the teen birth rate nearly 10 times higher than in The Netherlands (Centers for Disease Control and Prevention [CDC], 2006; Wijsen \& Van Lee, 2006). In 2006 and 2007, teen birth rates increased in the United States (Santelli, Orr, Lindberg, \& Diaz, 2009). In addition, the U.S. abortion rate is about twice as high (CDC, 2006; van Veen, Koedijk, Van den Broek, Op de Coul, De Boer, Van Sighem, \& Van der Sande, 2007; Wijsen \& Van Lee, 2006). In young women aged 15 to 24 years, HIV prevalence rate in The Netherlands is six times lower than in the United States (van Veen et al., 2007).

In both the United States and The Netherlands, disparities grow by income and education. Teens who are less educated and come from poorer families have higher rates of teen pregnancy, births, abortions, and STIs (De Graaf, Meijer, Poelman, \& Vanweesenbeeck, 2005; Finer \& Henshaw, 2006; Singh, Darroch, Frost, 2001). Researchers in both countries have also found that ethnicity influences teen pregnancy rates. Specifically, the pregnancy rates for Black and immigrant teens are significantly higher than those of White teens. However, among white girls, a much higher rate for teen pregnancy, birth, and abortion was found in the United States as compared with The Netherlands and other countries (Darroch, Singh, \& Frost, 2001; 
Brugman, M., Caron, S.L., Rademakers, J. Emerging adolescent sexuality: a comparison of Americanand Dutch college women's experiences. International Journal of Sexual Health: 2010, 22(1), 32-46

Feijoo, 2009; van Berlo, Wijsen, \& Vanweesenbeeck, 2005). In fact, for several decades, The Netherlands has been the forerunner in improving sexual and reproductive health and rights among all developing and developed countries.

How can two industrialized countries concurrently produce the highest and lowest teen pregnancy rate, births, and abortion rate? Clearly, there is a need to better understand teenagers' sexual behavior and what influences them.

American sexual health care is not as integrated in the general primary health care system. The United States has public and privately funded family-planning clinics that provide contraceptives. In rural counties, clinics are often the only places where women and girls can receive specialized family-planning care. "However, the high rate of clinic turnover and the lack of significant growth in clinic numbers suggest that limited funding and rising costs have hindered the further expansion and outreach of the clinic network to new geographic areas and hard-to-reach populations” (Frost, Frohwirth, \& Purcell, 2004, p. 213). Fewer U.S. clinics means contraception is more difficult to get and, as a result, possibly less familiar to use (Alan Guttmacher Institute [AGI], 2001). Adolescents should be certain of inexpensive, "confidential, nonjudgmental care,” writes AGI (2001, p. 6), yet in the United States, they frequently lack clear directions for getting contraceptives.

For decades in The Netherlands, girls and women up to age 22 have received free birth control. In addition, emergency contraception is much more generally accepted and available in The Netherlands than in the United States, where it is more likely to be regarded as "an abortifacient" (Cromer \& McCarthy, 1999, p. 292).

Use of contraceptives in The Netherlands significantly impacts the lower teen pregnancy rate (Braeken, Rademakers, \& Reinders, 2002; Santelli et al., 2009). Although young people in the United States and The Netherlands show similar sexual behavior, "the [Dutch] abortion rate is low because unplanned pregnancy is rare," concludes Ketting (1990, p. 32). The government-funded organization Youth Incentives notes that Dutch policy tries to empower young people to be responsible in their sexual activity (Braeken et al., 2002; Feijoo, 2001). The Dutch government places an importance on people controlling their own reproductive well-being.

The Netherlands also acknowledges teen sexuality as healthy and natural so long as both partners agree with what happens (Rademakers, 1991). Nearly 10 years ago, the organization Advocates for Youth noted that young people in The Netherlands were sexual responsible and treated with respect (Feijoo, 2009). The approach of "normalization" in The Netherlands is in stark contrast to the "dramatization" in the United States. In a qualitative study comparing the sexual attitudes and opinions of 130 U.S. and Dutch parents and teens, Schalet (2004) found 9 out of 10 U.S. parents forbid their teenagers to spend the night with a girlfriend or boyfriend at their house, whereas 9 out of 10 Dutch parents permitted such overnight stays. U.S. parents expect that teens have no authority over their sex life and, specifically, that young women cannot really be in love. Schalet writes that "hormones seem to be the first thing that comes to mind when U.S. parents are asked about teenagers” (p. 7). Dutch teens seem to talk about the use of contraceptives more openly with their parents, including discussion about taking responsibility for sex and considering the importance of one's own feelings (Schalet).

Research has found that persons with greater discomfort about the subject of sex avoid information on sexuality, are less likely to educate their children on sexuality issues, and use birth control more inconsistently than those who are comfortable (Fisher \& Fisher, 1999). However, a gap exists in crosscultural research comparing the sexual comfort of Dutch and American people.

It is estimated that between $74 \%$ and $95 \%$ of teen pregnancies are unintended (Abma et al., 1997; Chandra, Martinez, Mosher, Abma, \& Jones, 2005). Some researchers found that girls experience more feelings of guilt and shame than boys about sexuality (De Graaf et al., 2005). Tolman (2002) describes an American society that "desexualized girls' sexuality, substituting the desire for relationship and emotional connection for sexual feelings in their bodies." Tolman also illustrates a common belief that "girls are the objects of boys' sexual desire and have no desires of their own" (p. 5). The American literature shows a sexual double standard in which young women report how boys have different sex drives than girls and that male sexuality is afforded primacy (Kane \& Schippers, 1996).

To learn more about girls' actual sexual behavior, this study focused on the differences between U.S. and Dutch young women. While much of the cross-cultural research on adolescent sexuality reports rates of teen pregnancy, STIs, and use of contraceptives, the current study focused on U.S. and Dutch adolescent 
Brugman, M., Caron, S.L., Rademakers, J. Emerging adolescent sexuality: a comparison of Americanand Dutch college women's experiences. International Journal of Sexual Health: 2010, 22(1), $32-46$

sexual behavior and on what lies behind their behavior, including the sexual experiences of these teens (from first love/kissing to intercourse) and the factors influencing their views (such as friends, school, parents, church, doctors, and media).

\section{Purpose of This Study}

In this study, young Dutch and U.S. young college women were asked to reflect on when their sexuality emerged. Specifically, this study focused on adolescent sexual behavior, attitudes, and sexual comfort of girls during the time they were in high school in an effort to better understand why these two groups of teens appear to have vastly different experiences, which ultimately lead to stark differences in rates of teenage pregnancy, births, abortions, and STIs. The following research question was the focus of this study:

Is there a difference between sexual behaviors, attitudes, and comfort of young college women in The Netherlands and the United States during their period of adolescence?

\section{METHODOLOGY}

\section{The Sample}

An e-mail was sent to 400 randomly selected college women attending an American university and 400 college women attending a Dutch university, inviting them to complete an online survey. The women were aged between 18 and 22 years old. Two independent samples were randomly drawn from the female student population at an American and Dutch university, and these two groups both represent the female student population from which they were drawn in terms of ethnicity and age. The two universities were chosen because they are similar in enrollment, both located in a rural environment, and have similar academic departments and degree programs. The same women were invited to participate in an in-depth interview to discuss their sexual experiences while in high school. Ten women from each university agreed to be interviewed.

The final survey sample consisted of 151 female students attending the American university and 138 female students attending the Dutch university. The overall response rate was $36 \%$. The mean age of the American sample was 19.68 and of the Dutch sample 19.57 years old. The majority (96\% of U.S. women and $99 \%$ of Dutch women) identified their race/ethnicity as "White." The majority of participants (59\% U.S. and 54\% Dutch) described their parents' income as "middle." In terms of religious affiliation, the percentage of Catholic students was similar in both countries (26\% U.S. and 28\% Dutch). Twenty-one percent of the U.S. women and 18\% of the Dutch women in the sample selected "Protestant." Seventeen percent of the American sample was categorized as "Other," and 4\% of the Dutch sample selected "Other." Thirty-six percent of the U.S. college women and $51 \%$ of the Dutch college women selected "None" for religion. When asked how important religion was for them, a majority (53\% U.S. and 73\% Dutch) defined their religion as "not important."

\section{The Survey}

The survey asked Dutch and U.S. college women about their experiences related to sexuality during adolescence. The 26-item questionnaire was divided into four parts: five demographic questions, five opening questions, eight sexual behavior questions, and eight sexual attitude questions. Demographic questions asked for age, race/ethnicity, religion, importance of religion, and parents' income level, while opening questions asked about acceptability of first intercourse, ability to talk to parents, and experience with sexuality education. This information was used to describe the U.S. and Dutch samples.

The women were asked to reflect on their early sexual behavior. Questions asked what age they were if/when they first masturbated and experienced deep kissing, heavy petting, oral sex, and sexual intercourse. In addition, if they had engaged in sexual intercourse, they were asked how many partners they had in high school, their reason for having sex the first time, if they used protection, and what (if any) method of birth control was used.

The women were also asked to reflect on their attitudes about sexuality while in high school. Rating on a 5-point scale from "strongly agree" to "strongly disagree," women were asked to reflect on such things as their teenage beliefs about first sexual intercourse, if it would be OK with their parents and friends, and if they could be popular and feel grown-up without having engaged in sex. Each response was given a score from 1 to 5 , with 1 reflecting the most traditional and 5 representing the most liberal attitude. 
Brugman, M., Caron, S.L., Rademakers, J. Emerging adolescent sexuality: a comparison of Americanand

Dutch college women's experiences. International Journal of Sexual Health: 2010, 22(1), 32-46

\section{The Interviews}

Exactly 10 women from each country expressed interest in being interviewed face to face. These 20 young women did reflect the characteristics of the two larger samples in terms of age, ethnicity, religion, and parents' income level. In the current study, the generalizing terms "Dutch" and "U.S.” girls are used and refer to the two groups of only 10 young women who are from these two countries.

The questions to guide the interview were created for this study and concerned the girls' experiences from first dating to sexual intercourse and the external factors that possibly informed or influenced them, such as parents, education, doctors, friends, and the media. The researcher attempted to learn how U.S. and Dutch women form their views of their sexuality and how they perceived their early sexual experiences. The interview focused on their behaviors, attitudes, and comfort with sexuality. The college women answered the researcher with their own understanding of their emerging sexuality. They were given the opportunity to use their unique words, their personal vocabulary, their original (Dutch and English) language, their individual expressions, and their particular style. The researcher conducted both sets of interviews, and the interviews were held in two different languages (Dutch and English). The interviews were tape-recorded, and the audiotapes were transcribed into a written format and one common language (English) by the researcher. All identifiers were removed from the transcripts.

To analyze the in-depth interviews, the two lead researchers used an inductive method of analysis, which means that themes emerged from the data (Patton, 2002). The in-depth interviews were analyzed via the Listening Guide Method, a feminist method of analysis designed by Brown, Debold, Tappan, and Gilligan (1991; Madden, 2000). For this study, an independent-coder method was used, meaning that two different researchers coded the same material independently. Using the Listening Guide Method meant that both researchers read all in-depth interviews four different times through four different lenses, looking for themes and patterns. A theme was identified when a topic was discussed by a majority of the women (6 out of 10 U.S. or Dutch college women). The first time the interviews were read (the first lens), general themes and patterns were identified and the researchers tried to understand the story and the context. The second time, the researchers examined the narratives on the use of the first person by the women. This reading was also called a reading for "self." The third reading analyzed how they received and responded to external factors that possibly influenced their sexuality and relationships during their high school years. A fourth and last reading examined how they viewed the impact of socio-cultural messages (e.g., media, Internet, advertising) on their sexuality. The themes that emerged from the interviews were then organized under the areas of sexual behavior, attitudes, and comfort and are discussed below.

\section{RESULTS}

\section{Opening Questions}

The college women were asked three opening survey questions related to sexuality and sex education, including how much they discussed sexuality with their parents, if they received formal sexuality education before graduating from high school, and if they or their friends had various sexual experiences in high school. The results are presented in Table 1.

\section{[TABLE 1]}

The opening survey questions about sexuality provided a good setting for understanding the differences between the U.S. and Dutch college adolescent girls and young women. From the opening questions, one discovers that Dutch girls talk significantly more often with their parents about sexuality $\left(X^{2}=8.93, p=\right.$ $.03)$, and they have been given significantly more sexuality education in high school $\left(X^{2}=25.37, p<.00\right)$. The U.S. girls were taught significantly more about abstinence only $\left(X^{2}=31.64, p<.00\right)$, and during sexuality education lessons, the Dutch girls discussed the different ways of having sex more than the U.S. girls did $\left(X^{2}=6.48, p=.011\right)$. The opening questions also revealed that U.S. girls knew many more high school classmates who experienced an STI $\left(X^{2}=65.41, p<.00\right)$, used emergency contraception $\left(X^{2}=\right.$ 29.33, $p<.00)$, became pregnant resulting in an abortion $\left(X^{2}=61.41, p<.00\right)$, had a baby $\left(X^{2}=112.73, p<\right.$ $.00)$, and in some cases put the baby up for adoption $\left(X^{2}=16.03, p<.00\right)$.

\section{Sexual Behavior}

The women were asked eight survey questions about their sexual behavior, including if they had experienced any of following five sexual behaviors: masturbation, deep kissing, heavy petting, oral sex, and 
Brugman, M., Caron, S.L., Rademakers, J. Emerging adolescent sexuality: a comparison of Americanand 7 Dutch college women's experiences. International Journal of Sexual Health: 2010, 22(1), $32-46$

sexual intercourse; and if so, at what age, as well as three additional questions about how many sexual partners they had in high school, the main reason for first intercourse, and their birth control behavior. Results are presented in Table 2.

\section{[TABLE 2]}

The responses to specific survey questions about their sexual behavior revealed that more U.S. girls experienced various sexual behaviors in high school. Significantly more U.S. girls had experienced oral sex $\left(X^{2}=19.18, p<.00\right)$ and intercourse $\left(X^{2}=4.55, p=.03\right)$ compared with the Dutch girls. In addition, significantly more U.S. girls had experienced intercourse $(t=-3.2, p=.00)$, oral sex $(t=-4.28, p<.00)$, and heavy petting $(t=-5.3, p<.00)$ and experienced all three activities at an earlier age. The U.S. girls had significantly more sexual partners $\left(X^{2}=19.27, p=.00\right)$ and were less likely to say they used birth control compared with the Dutch girls $\left(X^{2}=10.16, p=.02\right)$. The U.S. girls were significantly more likely to say they had sex for the first time because of opportunity or peer or partner pressure, whereas the Dutch girls were more likely to say it was because of love $\left(X^{2}=13.74, p=.02\right)$.

The results of the survey questions on sexual behavior were confirmed in the in-depth interviews. From the in-depth interviews, many themes on sexual behaviors emerged. A theme was formed when a minimum of 6 out of 10 young college women had said so. All themes are presented in Table 3.

\section{[TABLE 3]}

After analyzing the 20 interviews, seven different themes emerged between the American and Dutch sample as they relate to girls' sexual behaviors. The U.S. college women talked extensively about being driven by hormones and peers and feeling unprepared when they experienced various forms of sexual behavior. They also talked about doing more sexually for their boyfriend's satisfaction (i.e., performing oral sex on him) and feeling as if he is in charge of the relationship. Interestingly, a few interviewed U.S. college women mentioned how different their brothers were treated by their parents who allowed their sons to have a girlfriend come over and let them be together in the boy's bedroom. Because of the small number of women (fewer than six) who told about this gender difference practiced at home, it did not form a theme for this study. Sample quotes supporting each of these themes are presented below.

- Driven by hormones and peers: "I was more like thinking with hormones and not really like with my head.... I think you have a lot more hormones going through you and you just want it, it is like a physical need, so I think that is why a lot of people get into trouble.”

- "All your friends are doing it [intercourse], they are talking about it, and if you haven't, you can't say anything, and also I was one of the last girls out of my friends to really do anything sexually with a guy, and they sort of picked on me about it."

- Unprepared: "The first time when we were having sex, it was an accident. It was not supposed to happen, but it did."

- Satisfying him: "I did not really enjoy it [fingering]. I mean I did it [hand job] because he liked it. Oral sex was with him too. I definitely enjoyed giving a blow job better than receiving it, because I was not really involved."

- He is in charge: "He was the one when anything sexual was involved; he was always the initiator, and I just kind of went along."

The U.S. college women's themes related to sexual behavior are in sharp contrast to those that emerged from the interviews with the 10 Dutch college women. In reflecting back to their younger years, the Dutch college women talked about having sexual experiences in the context of a loving relationship where mutual interest and open communication takes place, having control over their own bodies and desires, and planning ahead and using protection. Sample quotes to support these Dutch themes are presented below.

- Motivated by love: "We always had gone there together by train, so we knew each other very well. I had fallen in love with him, and then we became girlfriend and boyfriend! And after that we made love for the first time."

- Control of my own body: "I said what I wanted and what I did not want very clearly, and at a certain moment I thought, 'now I want to.”' 
- Ready for sexual intercourse: "It was more something like, what do we want exactly, and then we made a plan together about how far we wanted to go and what protection we would use."

\section{Sexual Attitudes}

The women were asked to reflect on their sexual attitudes while in high school, such as their beliefs about first sexual intercourse, if it would be OK with their parents and friends, and if they could be popular and grown-up without having engaged in sex. As can be seen in Table 4, there were no significant differences to specific attitude questions between the college women in these two countries, except on one item: The responses about sexual attitudes revealed that significantly more Dutch parents were accepting of their daughters having sex when they were in high school $\left(X^{2}=30.83, p<.00\right)$. Both samples revealed similar answers on the attitude questions about acceptance. The 20 U.S. and Dutch young college women did not believe that having sex as a teenager went against their own beliefs, even in a serious relationship. Both groups of young women thought it was OK to have sex as a teenager, and the same was true for the acceptance by friends on the idea that they had sex when they were in high school.

\section{[TABLE 4]}

From the in-depth interviews, nine distinctly different themes emerged between the American and Dutch sample as they relate to girls' sexual attitudes. See Table 3. External factors, such as their parents, friends, doctors, books, the media, and the culture they live in, were cited as having an impact on the girls' sexual attitudes.

While the survey results found no significant difference between the U.S. and Dutch college women regarding their parents' comfort with talking about sex, the 20 interviews told us a very different story. The U.S. college women discussed how their mothers did not educate them at all (except to warn them about sex), and that fathers only joked, if they spoke at all about sex. They recalled that their primary source of information was their (often uneducated) friends. Other themes that emerged included how schools had a "just say no" approach to sexuality and that they did little to counter the often unrealistic or dangerous portrayals of sexuality in the media which bombarded these girls during their high school years. Sample quotes supporting each of these themes related to sexual attitudes are presented below.

- Warning mothers and joking dads: "Well, she kind of was like, I really don't want you to be having sex before college."

- "I could not really talk with my dad about it [when I was in high school]. Now [since I am in college], I would say my dad would joke about me having sex and stuff like that, because he knows my boyfriend."

- Friends as primary source: "It was kind of mostly through like friends experimenting kind of thing..., but it was not anything we were formally educated on."

- "Just say no": "In seventh grade, they start to teach you about abstinence. I guess it was a formal sex education. They [my friends] took a really immature stand on it, just like laughing about it. Everyone was embarrassed to talk about it, so they just made jokes."

- Influence of media: "A lot of the [popular] movies in the high school setting are based like, I was like why don't I have that life, why don't I have a boyfriend? It gives you the impression that I am supposed to have a boyfriend, I am supposed to be sleeping with him by now, you know.”

In contrast to the interviews with the U.S. college women, the 10 Dutch college women painted a very different picture of possible influences on their sexual attitudes. The 10 Dutch parents, both mothers and fathers, were described as very open and involved in educating their daughters at a very young age about sexuality. The Dutch parents of these 10 young college women were not the only ones who had positive attitudes about sexuality. Schools and medical doctors, with their emphasis on the importance of sex in a loving relationship, were also seen as positive influences in The Netherlands. Another theme that emerged from the interviews with the Dutch women was that most of them recalled reading books on sexuality with their parents when they were young, which they felt had a positive influence on their sexual attitudes. The Dutch women also talked about their lack of interest in viewing pornography. Sample quotes to demonstrate these themes are presented below. 
Brugman, M., Caron, S.L., Rademakers, J. Emerging adolescent sexuality: a comparison of American_and 7 Dutch college women's experiences. International Journal of Sexual Health: 2010, 22(1), 32-46

- Parents as supporters and educators: "I told this to my mom as soon as I got home (after the first time I had sex), because we talk very open about this. My friend's mother also asked me how it was, if I had an orgasm and if he had one."

- Positive sexuality educators: "We had a video about being in love and also about what fingering meant and doing a hand job. We were told things about sex: that you first should have a relationship... that everything has to be mutual and agreed upon, a lesson about condoms, some of the basics, and anatomy."

- Realistic doctors: "The doctor told me that the pill was mainly to regulate the menstruation in my case, but when I used it regularly, I could also use it for contraception."

- Books at young ages: "A very important series of books to me were the [children's] series with titles, such as Deep Kissing to Making Love. In a nice way, you get to know those things. I started to collect them when I was in elementary school, and when I was 14, I had them all.

- $\quad$ No porn for me: "I am not interested in porn. I did see some things on TV sometimes, and I thought, 'I don't really need this.”'

\section{Sexual Comfort}

Eight distinctly different themes emerged related to girls' sexual comfort between the U.S. and Dutch sample from the 20 in-depth interviews. See Table 3. The 10 U.S. women were clearly less comfortable with their own bodies than their Dutch counterparts: The U.S. college women discussed that young and innocent girls don't have sex, and how most of them even saw sex as something bad and dirty. Most of the 10 U.S. college women had parents who were clearly uncomfortable compared with the Dutch; often the U.S. parents were completely silent on the topic of sexuality. These young women also discussed how their boyfriends were often uneducated about female sexuality, and that during high school, the girls were not comfortable with their boyfriends when they had sex. A fifth theme was related to the need to hide their sexual behavior with their boyfriend, especially when at home. Sample quotes to demonstrate these themes are presented below.

- Innocent girls don't have sex: "I am daddy's girl, and he would go ballistic if he knew that I was doing it and that stuff."

- Sex is dirty: "We use condoms, because I hate the mess it makes after. That is why we use them."

- Uncomfortable and silent parents: "Dad couldn't do 'the talk,' so I am the oldest one, and I kind of gave him [my brother] 'the talk.' I mean my father did not answer his questions."

- Boys are from Mars: "He was not good at it [fingering], ha ha. Well, you know, boys are boys. They are so different."

- Not at our house: "[Even now in college, my parents are like] she is having sex, and oh god. They still do it [rolling their eyes], and they still have a rule that there are no co-ed sleepovers in their house, not under their roof."

Unlike the U.S. college women, the Dutch college women expressed great comfort with sexuality. Three major themes emerged from the 10 in-depth interviews with the Dutch college women, including comfort with their own sexual pleasure, comfort with talking to their parents, being open with them about their sexual behavior, and comfort with their fathers. Sample quotes supporting these themes related to sexual comfort are presented below.

- We both enjoy sex: "He was a very sweet boy... so I could talk with him and hug him. We took our time, I got a positive feedback [about my first oral sex on him] —we both enjoyed lovemaking."

- Sleeping openly at parents' house: "My mom told me, get him over here for the weekend, he can sleep here at our house [in your bed], and I'll pick him up from the railway station with my car."

- Comfortable dads: "They [parents] thought it was fine [that we slept together]; dad just always made up a bed for us [me and my boyfriend] to sleep.

\section{DISCUSSION AND IMPLICATIONS}

This study aimed to provide a more in-depth look into the sexual experiences of college women during their period of emerging adolescence in the United States and The Netherlands. This quantitative and qualitative study is unique in its comparison of two groups of women who just finished adolescence and 

Brugman, M., Caron, S.L., Rademakers, J. Emerging adolescent sexuality: a comparison of Americanand 7
Dutch college women's experiences. International Journal of Sexual Health: 2010, 22(1), 32-46

were able to reflect on this period in which sexuality emerged. The women explained their sexual behavior from first love/kissing to intercourse. This study goes beyond pregnancy rates or a focus on intercourse and reveals clear examples of what it means to be a sexually responsible teen in The Netherlands and what it means to feel uncomfortable with sexuality in the United States. The results indicate that these two small samples of young women had very different experiences. While the Dutch young women seemed to own their bodies and sexuality, surrounded by sexually positive and comfortable parents, teachers, and doctors, the studied U.S. girls were left in the dark with their uneducated friends as their guide, surrounded by sexually silent or negative adults and unrealistic media.

The opening survey questions obviously set the contrasting experiences of the interviewed U.S. and Dutch college women. Previous studies have supported these differences between the two groups on unsheltered and more developed discussions on sexuality, finding a much greater openness at home and school in The Netherlands when it comes to sexuality (AGI, 2001; Feijoo, 2009). In addition, from the opening questions on sexual experiences in high school, one can conclude there is a high rate of unprotected sex by U.S. girls. The U.S. girls said they had less parental guidance and less formal sexual education and knew significantly more classmates who had experienced unplanned pregnancies and STIs. These findings support previous studies showing U.S. girls experiencing high rates of teen pregnancy, birth, and abortions in high school as compared with Dutch teens (Caron \& Moskey, 2002; Darroch et al., 2001; van Berlo et al., 2005).

Our survey results reveal more U.S. girls experiencing various sexual behaviors (intercourse, oral sex, heavy petting) in high school, earlier in life, with more partners, while less likely to use birth control. In addition, the U.S. girls were significantly more likely to say the reason for first intercourse was opportunity or peer and partner pressure, whereas the surveyed Dutch women said that love/commitment was the most important reason for first intercourse.

Furthermore, the results of the interviews on sexual behavior are in sharp contrast to the Dutch college women, who talked about taking their time to explore their sexuality and their own desires, planning ahead and using protection, and having sexual experiences in the context of a loving relationship where mutual interest and open communication occurred. Previous research supports these findings, noting that more U.S. than Dutch teens have engaged in various sexual behaviors during adolescence, and that U.S. teens show a less effective use of contraception (AGI, 2001; De Graaf et al., 2005; Santelli, Morrow, Anderson, \& Duberstein Lindberg, 2006). In addition, studies have found that Dutch teens feel really loved by their partners, and that love and intimacy are their reasons for having intercourse (Santelli et al., 2009; De Graaf et al., 2005; Ingham, 1998; Vogels \& Van der Vliet, 1990).

The themes derived from the U.S. interviews- "Satisfying him" and "He is in charge"-are examples of maintaining a sexual double standard, in that the young women reported how their boyfriends had different sex drives (Kane \& Schippers, 1996). Most interviewed U.S. women in this study granted a greater sexual freedom to boys. A minority of U.S. college women revealed that this sexual double standard also was practiced by some of their parents, who gave their sons more sexual privileges. An example of a negative consequence is the obstruction of using contraceptives by girls (Hertzog, 2008). None of the 10 Dutch college women had to deal with this old standard; it would be interesting to better examine this phenomenon in both countries in future research. A better understanding of girls' sexuality could be reached after studying if and how other Dutch girls deal with the sexual double standard.

As found in the opening survey questions, the positive approach to sexuality education in Dutch schools was offered in different classes and grades and focused on various ways of being sexual. The interviews on sexual attitudes supported these findings. The college women revealed how school contributed to their attitudes on sexuality. They discussed how their school emphasized the importance of sex within the context of a relationship, where love, pleasure, and equality are key components. This is unlike the U.S. girls, who, if they received sexuality education at all, had it in the later years of high school with emphasis on the negative consequences of sex.

Interestingly, the survey questions on sexual attitudes about the acceptance of having sex as a teenager revealed similar answers for both groups. Both the Dutch and the U.S. young college women said that having sex as a teenager was not against their beliefs and would have been OK with their friends. The American results from this study are similar to those found some years ago in a study by Caron and Moskey (2002), when a majority of respondents just out of high school said that having sex as a teenager was not against their beliefs and would have been OK with their friends. This suggests that Dutch and American young people both have positive attitudes about sex during adolescence. 
Brugman, M., Caron, S.L., Rademakers, J. Emerging adolescent sexuality: a comparison of Americanand Dutch college women's experiences. International Journal of Sexual Health: 2010, 22(1), 32-46

The survey responses about sexual attitudes disclosed significantly more Dutch parents than U.S. parents accepted their high school-age daughters having sex. The in-depth interviews amplified this statement with many stories about how, when they were very young, the Dutch girls read books with their parents that they felt had a positive influence on their sexual attitudes. Interestingly, a majority of the U.S. college women stated in the survey that they had at least one parent who was comfortable talking about sex. When the researcher asked the same question to the 10 U.S. college women during the interviews, they immediately gave the same answer and said that their parents felt comfortable with sex. However, when asked to give examples of their sexually comfortable fathers and mothers, the 10 U.S. young women suddenly denied this comfort and gave contradicting examples.

Ten U.S. college women said that none of their parents explained anything about sexuality in their younger years. A few mothers warned their daughters about the possible consequences of sex or told them to wait until college to have sex. And that was all. When their mothers asked, the teen daughters affirmed that they already knew everything about sex. The fact that their mothers asked only once if their daughters were well informed gave the 10 interviewed U.S. college women the idea that their mothers were comfortable with the topic. The U.S. fathers seemed completely invisible. They were silent, and a very few could only joke about sex. By silencing the topic of sexuality, these parents desexualized their daughters, denying that the girls were sexually active or wanting to believe that "the pill was for regulating my menstruation.” The 10 U.S. women's stories about their doctors and churches reinforced the same themes of silence and danger related to sex for American girls. The U.S. stories were in sharp contrast to the 10 Dutch stories in which realistic doctors positively influenced the girls in The Netherlands. The Dutch girls experienced doctors who did not focus on possible damaging consequences of sex; also lacking was a negative church influence. From the interviews with the 10 Dutch women, it remained unclear if religion had any influence on teens' sexual development, simply because none of them had a religious affiliation. This positive approach by the Dutch educational system and medical providers is well documented (AGI, 2001; Braeken et al., 2002; Cromer \& McCarthy, 1999; Schalet, 2004).

The group of U.S. college women discussed how much the media influenced their attitudes on sexuality, as well as those of their friends. Unrealistic portrayals of sexuality in the media (including the viewing of pornography) and uneducated friends were clearly powerful influences in shaping the attitudes of the U.S. sample. A big influence of friends, especially for U.S. teens, has been discussed in former research (AGI, 1999; Hoff, Greene, \& Davis, 2003; Ingham, 1998). Previous studies have documented how U.S. teens are exposed to unrealistic views on sexuality by the media, rather than on how to make healthy decisions (AGI, 2001; Wingood et al., 2001; Zurbriggen et al., 2007).

Lastly, the interview results on sexual comfort manifest the differences between two divergent groups of young women. Unlike the U.S. girls who hid their sexual behavior from their parents, knowing it was unacceptable, the Dutch felt unobstructed with their parents about sexual behavior. With their parents' knowledge and support, the Dutch girls slept openly with their boyfriends. The discomfort with sexuality in America versus comfort with sexuality in The Netherlands has been supported by the literature (Braeken et al., 2002; Caron \& Moskey, 2002; Rademakers, 1991; Schalet, 2004).

The current study also reveals sexually comfortable U.S. college women, despite stories of discomfort with comments that "sex is dirty," "innocent girls don't have sex," "satisfying him," and "he is in charge.” It would be interesting to conduct more research on girls' sexual comfort to better understand the ambiguous meaning of sexual comfort.

This study offers implications for how America might deal more effectively with sexuality issues. This study went beyond surveys about teen pregnancy rates and did not focus solely on sexual intercourse in the United States and The Netherlands. The current study examined what is behind this. The young women's stories focused on various sexual behaviors, attitudes, and comfort in their precollege years (from first love to intercourse).

When considering the vast differences between these two countries in teen pregnancy, births, abortions, and STI rates, one might attribute the lower rates in The Netherlands to the government-sponsored universal health care. The availability of free birth control for young people and health services is only part of the solution. In the United States, adults (from parents to teachers and health care providers) silence teen sexuality, assuming that teenagers know it all and reinforcing the idea that, as the American college women said in their interviews, "planning ahead for sex means a girl is a slut." Parents play an important role in the development of girls' sexuality, and both U.S. mothers and fathers do not step up as guides for their 
Brugman, M., Caron, S.L., Rademakers, J. Emerging adolescent sexuality: a comparison of American and Dutch college women's experiences. International Journal of Sexual Health: 2010, 22(1), $32-46$

daughters. U.S. girls felt "unprepared," and the adults' attitude of ignoring sexuality does not lead to responsible sexual behavior by teens. The current study confirms how important adults' information about sexuality is for young people. Adults can help adolescents by reading books at a young age, asking questions, including serious fathers who share experiences, and explaining unrealistic media messages.

Moreover, comprehensive sexuality education in U.S. schools, and not the promotion of abstinence, is a prominent distinction that adds to a different attitude on sexuality and a more healthy sexual development of adolescents. At school, many girls were told to wait to have sex and warned how dangerous it could be. Formal sexuality education should be based on research and presented in a positive, realistic way. Sexuality education should be taught in the context of a relationship, which happens in The Netherlands, where the importance of love, respect, and responsibility in relationships is emphasized.

Last but not least is the important role of the media. As the 10 U.S. college women clearly stated in the interviews, this is where they were getting messages about sexuality. The U.S. women in the study said that when they were teens, the media painted a picture of the reality. The 10 Dutch women said they were not interested in porn movies because of their unrealistic concept. Research has found that sexual content in the media predicts the initiation of adolescents' sexual activities and has a profound, negative effect on young girls' sexual development (Brown, L'Engle, Pardun, Kenneavy, \& Jackson, 2006; Zurbriggen et al., 2007). The media in the United States does not offer young people positive, realistic media messages or long-term educational campaigns on sexuality like those found in The Netherlands (AGI, 2001; Zurbriggen et al., 2007).

In addition, if schools and parents assist girls in media literacy efforts, they learn through frank and direct conversation to resist the message that how they look is all that matters (Zurbriggen et al., 2007). There is a need for reform in this area; Santelli et al. (2009) conclude that, at the state and national levels, American society should create a consensus in accepting normal and healthy teenage sexuality.

It is important to acknowledge some of the limitations of this study. One limitation is the sample itself. The study was limited to a small survey sample of women in college $(n=289)$ and the in-depth study involved interviews with 20 women. Volunteering for the sample may have been determined by characteristics, such as submissiveness, availability, or special interest in the sexuality subject. During the interviews, all 20 interviewed college women appeared to be comfortable talking about sexuality and their experiences. When a minimum of six college women made similar comments, a theme was formed.

In the current study, these 6 to 10 women were generalized and referred to as "Dutch" and "U.S." girls, which can initially confuse the reader, given the total sample size of 20. Research with more women and not just those in college would provide a more comprehensive understanding of young women's sexual experiences.

A second limitation is that retrospective material was used in which college women were asked to reflect on their high school experiences. In retrospective research, people may not be able to accurately recall their earlier attitudes and behaviors. However, Spanier (1976) studied the use of retrospective material in sexological research and concluded that because our culture puts an enormous emphasis on sexuality, it is easier for people to remember their sexual experiences.

The survey response rate for this study was $36 \%$, limiting generalizations to the population. On the one hand, it is assumed that the students most interested in responding to this survey were sexually active- the group this study was most interested in understanding. On the other hand, one can imagine that other potential respondents were so busy with coursework or so inhibited by questions concerning their sexuality that they did not respond. Perhaps those choosing to participate in this study represent a unique group of college women who are more comfortable with their sexuality as compared with others who did not respond. This potential bias could have momentous effects on the results and any conclusion that might be drawn. How can the sexual experiences of college women be described when fewer than half were willing to say what they did? Therefore, not only is more research needed in this area, but also further studies should focus more on obtaining higher response rates.

Although the interviews allowed for more in-depth understanding and offset some of the concerns about the survey findings, these same concerns about who was willing to participate in the interviews could be raised. The irony is that despite the potential bias of having those most comfortable with sexuality be the ones most willing to participate in interviews, many of the U.S. college women clearly reflected great discomfort with sexuality. 
Brugman, M., Caron, S.L., Rademakers, J. Emerging adolescent sexuality: a comparison of Americanand Dutch college women's experiences. International Journal of Sexual Health: 2010, 22(1), 32-46

It is important to acknowledge that the methodological design of the study was a major strength and may offset some of the limitations discussed above. A combination of quantitative and qualitative research methods, commonly referred to as "triangulation," was used to ensure robustness and consistency in the findings (Patton, 2002).

In conclusion, cross-cultural studies are important to provide a comparison with which to measure our success or failure in this area. Americans have much to learn from other countries like The Netherlands which has been able to assist young people in their sexual development. The low pregnancy, birth, abortion, and STI rates in The Netherlands provide hope and a challenge to the United States in considering what is possible. Affordable, accessible family-planning services, more and earlier formal sexuality education, open attitudes of parents and other adults, and more realistic and positive media messages would allow U.S. girls to develop in sexually healthy ways. Being sexually healthy is not only important for the girls' own pleasure and happiness as they grow up but also is important for their partners and society.

\section{REFERENCES}

1. Abma, J. C. , Chandra, A. , Mosher, W. D. , Peterson, L. S. andPiccinino, L. J. (1997) Fertility, family planning, and women's health: New data from the 1995 National Survey of Family Growth National Survey of Family Growth. National Center for Health Statistic — DHHS publication no. (PHS) 971995. Vital and Health Statistic, 23(19)

2. Alan Guttmacher Institute (1999) Survey on teen peer pressure. Author - Retrieved February 14, 2009, from http://www.teenpregnancy.org

3. Alan Guttmacher Institute (2001) Can more progress be made? Teenage sexual and reproductive behavior in developed countries Author - Retrieved February 14, 2009, from http://www.guttmacher.org/pubs/euroteens_summ.html

4. Braeken, D. , Rademakers, J. andReinders, J. (2002) Welcome to The Netherlands: A journey through the Dutch approach to young people and sexual health Youth Incentives, Utrecht, The Netherlands

5. Brown, J. D. , L'Engle, K. L. , Pardun, C. J. , Kenneavy, K. andJackson, C. (2006) Sexy media matter: Exposure to sexual content in music, movies, television, and magazines predicts Black and White adolescents' sexual behavior. Pediatrics 117:4 , pp. 1018-1027.

6. Brown, L. M. , Debold, E. , Tappan, M. andGilligan, C. Kurtines, W. M. andGewirtz, J. L. (eds) (1991) Reading narratives of conflict and choice for self and moral voices: A relational method. Handbook of moral behavior and development: Vol. 2. Research pp. 25-51. Erlbaum, Hillsdale, NJ

7. Caron, S. L. andMoskey, E. G. (2002) Changes over time in teenage sexual relationships: Comparing the high school class of 1950, 1975, and 2000. Adolescence 37:147, pp. 515-526. [ csa ]

8. Centers for Disease Control and Prevention (2006) Trends in reportable sexually transmitted diseases in the United States, 2005: National surveillance data for Chlamydia, gonorrhea, and syphilis Author , Atlanta, GA - Retrieved February 12, 2009, from http://www.cdc.gov/std/stats05/trends2005.htm

9. Chandra, A. , Martinez, G. M. , Mosher, W. D. , Abma, J. C. andJones, J. (2005) Fertility, family planning, and reproductive health of U.S. women: Data from the 2002 National Survey of Family Growth. National Center for Health Statistics. Vital Health Stat 23:25

10. Cromer, B. A. andMcCarthy, M. (1999) Family-planning services in adolescent pregnancy prevention: The views of key informants in four countries. Family Planning Perspectives 31:6, pp. 287-293. [ csa ]

11. Darroch, J. E. , Singh, S. andFrost, J. J. (2001) Differences in teenage pregnancy rates among five developed countries: The roles of sexual activity and contraceptive use. Family Planning Perspectives 33 , pp. 244-250. [ csa ]

12. De Graaf, H. , Meijer, S. , Poelman, J. andVanweesenbeeck, I. (2005) Seks onder je 25e: Seksuele gezondheid van jongeren in Nederland anno 2005 Eburon, Delft, The Netherlands - [Sex under 25: Sexual health of youth in The Netherlands in 2005]. RNG-studies nr. 7

13. Feijoo, A. N. , Alford, S. andHauser, D. (2009) Adolescent sexual health in Europe and the U.S. Why the difference? Advocates for Youth, Washington, DC

14. Finer, L. B. andHenshaw, S. K. (2006) Disparities in rates of unintended pregnancy in the United States, 1994 and 2001. Perspectives on Sexual and Reproductive Health 38:2 , pp. 90-96.

15. Fisher, W. A. andFisher, J. D. Rosen, R. , Davis, C. andRuppel, H. (eds) (1999) Understanding and promoting sexual and reproductive health behavior. Annual review of sex research 9 , pp. 39-76. Society for the Scientific Study of Sex, Mason City, IA

16. Frost, J. J. , Frohwirth, L. andPurcell, A. (2004) The availability and use of publicly funded familyplanning clinics: U.S. trends, 1994-2001. Perspectives on Sexual and Reproductive Health 36:5 , pp. $206-$ 215. 
Brugman, M., Caron, S.L., Rademakers, J. Emerging adolescent sexuality: a comparison of Americanand 7
Dutch college women's experiences. International Journal of Sexual Health: 2010, 22(1), 32-46

17. Hertzog, J. L. (2008) What about the gray area? College women's reflections on the sex talk and abstinence. Families in Society: The Journal of Contemporary Social Services 89:2, pp. 312-322.

18. Hoff, T. , Greene, L. andDavis, J. (2003) National survey of adolescents and young adults: Sexual health knowledge, attitudes, and experiences The Henry Kaiser Family Foundation, Washington, DC Retrieved October 31, 2006, from http://www.kff.org/youthhivstds/upload/National-Survey-of-Adolescentsand-Young-Adults.pdf

19. Ingham, R. (June 1998) Exploring interactional competence: Comparative data from the United Kingdom and The Netherlands on young people's sexual development. Paper presented at the 24th meeting of the International Academy of Sex Research Sirmione, Italy

20. Kane, E. andSchippers, M. (1996) Men's and women's beliefs about gender and sexuality. Gender \& Society 10:5 , pp. 650-665.

21. Ketting, E. Hekma, G. , van Stolk, B., van Heerikhuizen, B. andKruithof, B. (eds) (1990) De seksuele revolutie van jongeren [Young people's sexual revolution]. Het Verlies van de Onschuld: Seksualiteit in Nederland: Groningen, The Netherlands pp. 69-84. Wolters-Noordhoff

22. Madden, M. (2000) The good girl/bad girl dilemma: Exploring rural Maine girls' sexual desires, behavior, and relationships, Doctoral dissertation . University of Maine — Dissertation Abstracts International, AAT 9995655

23. Patton, M. Q. (2002) Qualitative research \& evaluation methods, 3rd ed, Sage Publications , Thousand Oaks, CA

24. Rademakers, J. (1991) Contraception and interaction: The prevention of unwanted pregnancy by teenagers in The Netherlands, Utrecht, Dissertation — ISBN 90-9004016-1

25. Santelli, J. S. , Morrow, B. , Anderson, J. E. andDuberstein Lindberg, L. (2006) Contraceptive use and pregnancy risk among U.S. high school students, 1991-2003. Perspectives on Sexual and Reproductive Health $38: 2$, pp. 107-111.

26. Santelli, J. S. , Orr, M. , Lindberg, L. D. andDiaz, D. C. (2009) Changing behavioral risk for pregnancy among high school students in the United States, 1991-2007. Journal of Adolescent Health 44:7 , pp. 2532.

27. Schalet, A. (2004) Must we fear adolescent sexuality?. Medscape General Medicine 6:4 , pp. 1-24. — Retrieved January 16, 2005, from http://www.medscape.com/viewarticle/494933

28. Singh, S. , Darroch, J. E. andFrost, J. J. (2001) Socioeconomic disadvantage and adolescent women's sexual and reproductive behavior: The case of five developed countries. Family Planning Perspectives. 33 , pp. 251-289. [ csa ]

29. Spanier, G. B. (1976) Use of recall data in survey research on human sexual behavior. Social Biology 23:3, pp. 244-253.

30. Tolman, D. L. (2002) Dilemmas of desire: Teenage girls talk about sexuality Harvard University Press Cambridge, MA

31. van Berlo, W. , Wijsen, C. andVanweesenbeeck, I. (2005) Gebrek aan regie, een kwalitatief onderzoek naar de achtergrond van tienerzwangerschappen, [Not enough control, a qualitative study on the background of teen pregnancies] Rutgers Nisso Group, Utrecht, The Netherlands

32. van Veen, M. G. , Koedijk, F. D. H. , Van den Broek, I.V. F., Op de Coul, E.L. M., Van De Boer, I. M. , Sighem, A. I. andVan der Sande, M. A. B. (2007) Sexually transmitted infections in The Netherlands in 2006 Epidemiology and Surveillance, Center for Infectious Disease Control. National Institute for Public Health and the Environment , Bilthoven, The Netherlands - Retrieved February 12, 2009, from http://www.rivm.nl/bibliotheek/rapporten/210261003.html[Rates calculated using Netherlands population data: CIA World Factbook.]

33. Vogels, T. andVan der Vliet, R. W. F. (1990) Jeugd en seks: Gedrag en gezondheidsrisico's bij scholieren [Youth and sex: Behavior and health risks of middle and high school students] SDU, Den Haag, The Netherlands

34. Wijsen, C. andVan Lee, L. (2006) National abortion registration, 2005 Rutgers Nisso Groep , Utrecht, The Netherlands

35. Wingood, G. M. , DiClemente, R. J. , Harrington, K. , Davies, S. , Hook III, E. W. andOh, K. M. (2001) Exposure to X-rated movies and adolescents' sexual and contraceptive-related attitudes and behaviors. Pediatrics 107:5, pp. 1116-1119.

36. Zurbriggen, E. L. , Collins, R. L. , Lamb, S. , Roberts, T. , Tolman, D. L.Ward, L. M. et al. (2007) Report of the APA Task Force on the sexualization of girls American Psychological Association, Washington, DC 
Brugman, M., Caron, S.L., Rademakers, J. Emerging adolescent sexuality: a comparison of Americanand Dutch college women's experiences. International Journal of Sexual Health: 2010, 22(1), 32-46

\section{TABLES}

TABLE 1. Responses to opening questions of U.S. and Dutch college women

\begin{tabular}{|c|c|c|c|c|}
\hline & U.S. $(N \cdot 151)$ & $\mathrm{NL}(N \cdot 138)$ & $x^{2}$ & SIG \\
\hline \multicolumn{5}{|c|}{ How much did you discuss sexuality issues ${ }^{*}$ with your parents in high school? } \\
\hline We never talked about sex issues. & $24 \%$ & $16 \%$ & \multirow[t]{4}{*}{8.93} & \multirow[t]{4}{*}{$p \cdot .03$} \\
\hline We talked about sex issues occasionally. & $49 \%$ & $65 \%$ & & \\
\hline We talked about sex issues several times. & $19 \%$ & $15 \%$ & & \\
\hline We talked about sex issues regularly. & $9 \%$ & $4 \%$ & & \\
\hline \multirow{2}{*}{\multicolumn{5}{|c|}{$\begin{array}{l}\text { - sexual intercourse, birth control, STIs, or pregnancy } \\
\text { Did you receive formal sexuality education before qraduating from hiah school? }\end{array}$}} \\
\hline & & & & \\
\hline I did not receive formal sex education. & $3 \%$ & $2 \%$ & \multirow[t]{4}{*}{25.37} & \multirow[t]{4}{*}{$p<.00$} \\
\hline I had one to two class sessions devoted to sex. & $46 \%$ & $44 \%$ & & \\
\hline There was an entire class devoted to sex. & $46 \%$ & $29 \%$ & & \\
\hline Sexuality education was covered in many of the classes. & $5 \%$ & $25 \%$ & & \\
\hline \multicolumn{5}{|c|}{ How would you best describe your sexuality education? Check all that apply } \\
\hline I did not receive formal sex education. & $3 \%$ & $2 \%$ & 1.06 & $p \cdot .304$ \\
\hline Biological aspects. & $94 \%$ & $99 \%$ & 4.85 & $p \cdot .028$ \\
\hline Abstinence only until marriage. & $35 \%$ & $7 \%$ & 31.64 & $p<.000$ \\
\hline Being in love and having a relationship. & $55 \%$ & $55 \%$ & 0.00 & $p \cdot .986$ \\
\hline Different ways of having sex. & $44 \%$ & $59 \%$ & 6.48 & $p \cdot .011$ \\
\hline \multicolumn{5}{|c|}{ Did you or someone you know in high school ever experienced the following: } \\
\hline Used emergency contraception. & $57 \%$ & $26 \%$ & 29.33 & $p<.000$ \\
\hline Had an abortion. & $49 \%$ & $8 \%$ & 61.41 & $p<.000$ \\
\hline Gave baby up for adoption. & $11 \%$ & $1 \%$ & 16.03 & $p<.000$ \\
\hline Had a baby and cared for the baby. & $73 \%$ & $12 \%$ & 112.73 & $p<.000$ \\
\hline Had a sexually transmitted infection. & $51 \%$ & $8 \%$ & 65.41 & $p<.000$ \\
\hline
\end{tabular}



Brugman, M., Caron, S.L., Rademakers, J. Emerging adolescent sexuality: a comparison of Americanand 7
Dutch college women's experiences. International Journal of Sexual Health: 2010, 22(1), 32-46

TABLE 2. Sexual behaviors of U.S. and Dutch college women

\begin{tabular}{|c|c|c|c|c|}
\hline & U.S. $(N \cdot 151)$ & $\mathrm{NL}(N \cdot 138)$ & $x^{2}$ & SIG \\
\hline \multicolumn{5}{|l|}{ High School Sexual Behavior } \\
\hline Masturbation & $76 \%$ & $80 \%$ & 0.77 & $p \cdot .379$ \\
\hline Deep kissing & $96 \%$ & $88 \%$ & 5.95 & $p \cdot .015$ \\
\hline Heavy petting & $95 \%$ & $82 \%$ & 11.71 & $p \cdot .001$ \\
\hline Oral sex & $88 \%$ & $67 \%$ & 19.18 & $p<.000$ \\
\hline Sexual Intercourse & $84 \%$ & $74 \%$ & 4.55 & $p \cdot .033$ \\
\hline \multicolumn{5}{|l|}{ Mean Age of First Sexual Behavior } \\
\hline Mean age of masturbation & $14.0 \mathrm{yr}$ & $13.7 \mathrm{yr}$ & 0.802 & $p \cdot .423$ \\
\hline Mean age of deep kissing & $14.9 \mathrm{yr}$ & $15.1 \mathrm{yr}$ & -0.958 & $p \cdot .339$ \\
\hline Mean age of heavy petting & $15.6 \mathrm{yr}$ & $16.8 \mathrm{yr}$ & -5.343 & $p<.000$ \\
\hline Mean age of oral sex & $16.2 \mathrm{yr}$ & $17.2 \mathrm{yr}$ & -4.282 & $p<.000$ \\
\hline Mean age of sexual intercourse & $16.7 \mathrm{yr}$ & $17.4 \mathrm{yr}$ & -3.198 & $p \cdot .002$ \\
\hline \multicolumn{5}{|c|}{ Number of Sexual Partners in High School } \\
\hline No partners in high school & $36 \%$ & $46 \%$ & 19.27 & $p \cdot .001$ \\
\hline One partner & $31 \%$ & $40 \%$ & & \\
\hline Two partners & $14 \%$ & $10 \%$ & & \\
\hline Three or more partners & $19 \%$ & $4 \%$ & & \\
\hline \multicolumn{5}{|l|}{ Main Reason for First Intercourse } \\
\hline Love/commitment & $59 \%$ & $73 \%$ & 13.74 & $p \cdot .017$ \\
\hline Physical attraction & $4 \%$ & $12 \%$ & & \\
\hline Opportunity/excitement & $16 \%$ & $8 \%$ & & \\
\hline Partner pressure & $8 \%$ & $4 \%$ & & \\
\hline Peer/social pressure & $4 \%$ & $0 \%$ & & \\
\hline Other & $9 \%$ & $3 \%$ & & \\
\hline \multicolumn{5}{|l|}{ Birth Control Use in High School } \\
\hline We always used birth control. & $70 \%$ & $85 \%$ & 10.16 & $p \cdot .017$ \\
\hline We did not use every time. & $28 \%$ & $12 \%$ & & \\
\hline We never used birth control. & $2 \%$ & $3 \%$ & & \\
\hline
\end{tabular}


TABLE 3. Themes related to sexual behavior, attitudes, and comfort that emerged from 20 in-depth interviews with U.S. and Dutch college women

\begin{tabular}{ll}
\hline Themes of U.S. Girls & Themes of Dutch Girls \\
\hline $\begin{array}{l}\text { SEXUAL BEHAVIOR } \\
\text { Driven by hormones and peers }\end{array}$ & $\begin{array}{l}\text { Motivated by love } \\
\text { Unprepared }\end{array}$ \\
$\begin{array}{l}\text { Satisfying him } \\
\text { Re is in charge }\end{array}$ & \\
SEXUAL ATTITUDES & \\
Warning mothers and joking dads & Parents as supporters and educators \\
Friends as primary source & Positive sexuality educators \\
Just say no & Realistic doctors \\
Influence of media & Books at young ages \\
& No porn for me \\
SEXUAL COMFORT & \\
Innocent girls don't have sex & We both enjoy sex \\
Sex is dirty & Sleeping openly at parents' house \\
Uncomfortable and silent parents & Comfortable dads \\
Boys are from Mars & \\
Not at our house & \\
\hline
\end{tabular}

TABLE 4. Percent of agreement to sexual attitudes of U.S. and Dutch college women

\begin{tabular}{|c|c|c|c|c|}
\hline & U.S. $(N \cdot 150)$ & $\mathrm{NL}(N \cdot 137)$ & $x^{2}$ & SIG \\
\hline $\begin{array}{l}\text { Having sex as a teenager went against my beliefs, even in a } \\
\text { serious relationship. }\end{array}$ & $13 \%$ & $12 \%$ & 2.48 & $p \cdot .479$ \\
\hline I believed it was OK to have sex as a teenager. & $72 \%$ & $71 \%$ & 0.11 & $p \cdot .991$ \\
\hline $\begin{array}{l}\text { If I had sex as a teenager, it would have been OK with my } \\
\text { parents/guardians. }\end{array}$ & $28 \%$ & $57 \%$ & 30.83 & $p<.000$ \\
\hline If I had sex as a teenager, it would have been OK with my friends. & $91 \%$ & $82 \%$ & 6.80 & $p \cdot .078$ \\
\hline $\begin{array}{l}\text { At least one of my parents/guardians felt comfortable talking to } \\
\text { me about sex. }\end{array}$ & $61 \%$ & $52 \%$ & 4.44 & $p \cdot .218$ \\
\hline $\begin{array}{l}\text { If I had sex with my boyfriend, it would make our relationship } \\
\text { stronger. }\end{array}$ & $35 \%$ & $40 \%$ & 1.28 & $p \cdot .734$ \\
\hline I could be popular without having sex. & $90 \%$ & $90 \%$ & 4.52 & $p \cdot .210$ \\
\hline I could be grown-up without having sex. & $87 \%$ & $82 \%$ & 1.28 & $p \cdot .734$ \\
\hline
\end{tabular}

